\title{
Improvement in Impact Energy Absorption of UD-CFRP by Sub-Micron Glass Fiber into Its Matrix
}

\author{
Ryotaro Murayama1*, Kiyotaka Obunai'2, Kazuya Okubo², Li Bao \\ ${ }^{1}$ Graduate School of Doshisha University, Kyoto, Japan \\ ${ }^{2}$ Department of Mechanical Engineering, Doshisha University, Kyoto, Japan \\ ${ }^{3} \mathrm{R} \&$ D Center, NIPPON MUKI Co., Ltd., Yuki, Ibaraki, Japan \\ Email: *cyjg1503@mail4.doshisha.ac.jp
}

How to cite this paper: Murayama, R., Obunai, K., Okubo, K. and Bao, L. (2021) Improvement in Impact Energy Absorption of UD-CFRP by Sub-Micron Glass Fiber into Its Matrix. Open Journal of Composite Materials, 11, 82-93.

https://doi.org/10.4236/ojcm.2021.114007

Received: July 7, 2021

Accepted: September 10, 2021

Published: September 13, 2021

Copyright $\odot 2021$ by author(s) and Scientific Research Publishing Inc. This work is licensed under the Creative Commons Attribution International License (CC BY 4.0).

http://creativecommons.org/licenses/by/4.0/

\begin{abstract}
CFRPs have high strength despite low density, but little impact resistance. In addition, the debonding of the interface between reinforcement fiber and matrix causes one of the fractures of FRPs. Therefore, the purpose of this study is to investigate the interfacial bonding characteristics between the reinforcement fiber and matrix of FRPs, not only under static loading but also under dynamic loading. Moreover, an effective method to improve the impact resistance of FRPs from the viewpoint of interfacial bonding characteristics was proposed. First, two types of UD-FRPs in which the reinforcement fiber was glass fiber or carbon fiber, were prepared to investigate the energy absorption under a bending load. A bending load was applied to the specimen statically and dynamically to measure the energy absorption until failure. The interfacial bonding characteristics between the reinforcement fiber and matrix were measured using a fragmentation method with a single fiber-embedded specimen. A dynamic tensile load was applied to the specimen using a tensile-type split Hopkinson pressure bar apparatus. Test results showed that the energy absorption of UD-CFRP decreased with an increase in strain rate, whereas that of UD-GFRP increased with an increase in strain rate. When the epoxy resin was modified by adding sub-micron glass fiber, both the interfacial shear strength between the carbon fiber and matrix, and the energy absorption of UD-CFRP improved.
\end{abstract}

\section{Keywords}

Energy Absorption, Split Hopkinson Pressure Bar Method, Interfacial Shear Strength, Strain Rate 


\section{Introduction}

Carbon fiber reinforced plastics (CFRPs) are a class of advanced composite materials that are well known for their high strength despite their low density [1]. At present, CFRPs are not only applied in exterior parts, but also in essential parts of automobiles, such as the chassis [2] [3]. It is known that the impact resistance of CFRPs may be inferior to that of glass fiber-reinforced plastics (GFRPs) [4]. When considering the application of CFRPs in the automobile industry, the impact resistance of CFRPs must be improved to ensure the safety and reliability of automobiles [5]. Previous researchers have suggested that the impact resistance of CFRPs can be enhanced by optimizing the laminate configuration of CFRPs. Odagiri et al. proposed the concept of interlayer-toughened $\mathrm{CF} /$ ppoxy prepreg, in which particles made from thermoplastic were dispersed. They claimed that, owing to the presence of an interlayer, the propagation of transverse cracks to interlaminar delamination could be effectively suppressed, thereby improving the impact resistance [6]. Nagai et al. also claimed that decreasing the difference in the fiber orientation angle between lamination improves the energy absorption of CFRPs [7]. However, these methods primarily focus on the suppression of macroscopic debonding, such as interlaminar crack propagation under impact loading. Few studies have focused on microscopic debonding, such as interfacial debonding between the fiber and matrix under impact loading.

Therefore, the purpose of this study is to investigate the interfacial bonding characteristics between the reinforcement fiber and matrix of FRPs, not only under static loading but also under dynamic loading. Moreover, we propose an effective method to improve the impact resistance included energy absorption of FRPs from the viewpoint of interfacial bonding characteristics. It can be improved the energy absorption and interfacial properties of FRP easily in various strain rate conditions. First, two types of UD-FRPs in which the reinforcement fiber was glass fiber or carbon fiber, were prepared to investigate the energy absorption under a bending load. A bending load was applied to the specimen statically and dynamically to measure the energy absorption until failure. The interfacial bonding characteristics between the reinforcement fiber and matrix were measured using a fragmentation method with a single fiber-embedded specimen. A dynamic tensile load was applied to the specimen using a tensile-type Split Hopkinson Pressure Bar apparatus.

\section{Materials and Methods}

\subsection{Materials}

Thermoset epoxy resin (JER-828, Mitsubishi Chemical) was used as the matrix of the FRP, and Cure 113 (Mitsubishi Chemical) was used as the curing agent. Two types of inorganic fibers of glass fibers (MS253, Asahi fiber glass) and carbon fibers (TR30S, Mitsubishi chemical) were prepared for use as the reinforcing fibers. Table 1 shows material properties of matrix and reinforcement. The 
Table 1. Material properties of matrix and reinforcement.

\begin{tabular}{ccccc}
\hline & $\begin{array}{c}\text { Diameter } \\
{[\mu \mathrm{m}]}\end{array}$ & $\begin{array}{c}\text { Young's modulus } \\
{[\mathrm{GPa}]}\end{array}$ & $\begin{array}{c}\text { Tensile strength } \\
{[\mathrm{MPa}]}\end{array}$ & $\begin{array}{c}\text { Fracture strain } \\
{[\%]}\end{array}$ \\
\hline Epoxy resin & & 2.66 & 71.8 & 3.90 \\
Carbon fiber & 7 & 235 & $4.12 \times 10^{3}$ & 1.80 \\
Glass fiber & 10 & 73.0 & $3.49 \times 10^{3}$ & 4.80 \\
\hline
\end{tabular}

single fiber tensile test was also conducted to obtain the relation between fiber length and fiber strength. The test velocity was $0.5 \mathrm{~mm} / \mathrm{min}$, and then at least 15 specimens were tested. The Weibull distribution used in this study is given by Equation (1) [8]. The Weibull parameters of each fiber, as obtained by the single fiber tensile test, are also listed in Table 2. Figure 1 also illustrates the Weibull plot of the tensile strength of the single fibers.

$$
F(\sigma)=1-\mathrm{e}^{\left\{-\frac{L}{L_{0}}\left(\frac{\sigma_{f}}{\sigma_{0}}\right)^{m_{f}}\right\}}
$$

where, $F(\sigma)$ is cumulative break probability, $L, L_{0}$ are fiber length and gage length of specimen, $\sigma_{f}$ is fiber strength, $\sigma_{0}, m_{f}$ are scale and shape parameter, respectively.

In this study, the sub-micron glass fiber (EFMW-1700, Nippon Muki) was used as the modifier of the resin matrix. The diameter and length of it are 0.69 $\mu \mathrm{m}$ and $71.6 \mu \mathrm{m}$, respectively.

\subsection{Fabrication of Modified Resin Matrix}

The absorbed water of the modifier of the submicron glass fiber (sGF) was eliminated by heating to obtain the modified resin matrix. After water elimination, a controlled amount of sub-micron glass fiber was added $0.30 \mathrm{wt} \%$ and dispersed into epoxy resin by stirring at $5000 \mathrm{rpm}$ for $30 \mathrm{~min}$. After dispersion, the curing agent was added to the modified resin to fabricate the composites.

\subsection{Fabrication of Uni-Directional (UD) FRP}

The hand lay-up technique was employed to fabricate the UD-FRP. First, a unidirectional fiber preform was prepared by winding the fiber tows onto an aluminum plate. The matrix resin was impregnated into the fiber preform using a roller, and eight sheets of resin-impregnated fiber preform were stacked. After stacking, the preform and resin were preheated by heat pressing under $0.86 \mathrm{MPa}$ at $80^{\circ} \mathrm{C}$ for $1 \mathrm{~h}$. Then, the temperature of the heat plate was increased to $150^{\circ} \mathrm{C}$ and kept constant for $3 \mathrm{~h}$ for hardening. The fiber volume fractions of the fabricated UD-GFRP and UD-CFRP were approximately $20 \%$ - 30\%, respectively. The fabricated UD-FRP was cut in parallel with the fibers using a diamond cutter, and, finally, a strip-shaped specimen of size $80 \times 10 \times 2.5 \mathrm{~mm}^{3}$ was prepared.

\subsection{Fabrication of Single Fiber Composite (SFC)}

A single fiber-embedded specimen was fabricated. The appropriate tensioned 


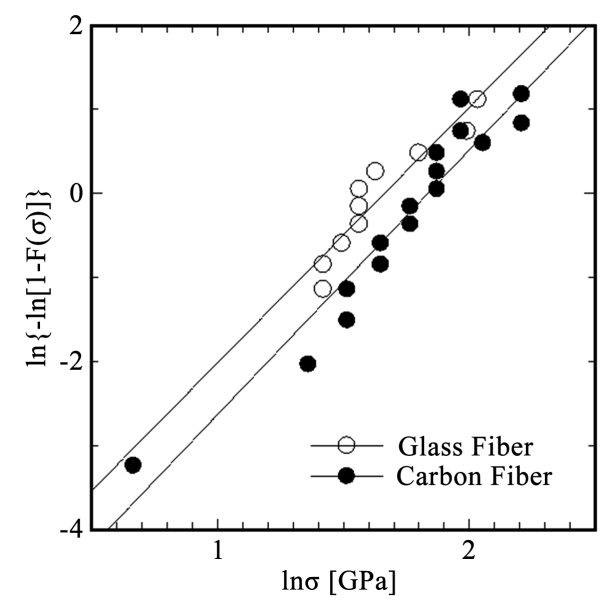

Figure 1. Weibull plot of carbon and glass fiber.

Table 2. Shape parameter and scale parameter of each fiber.

\begin{tabular}{ccc}
\hline & Shape parameter $m_{f}[-]$ & Scale parameter $\sigma_{0}[\mathrm{GPa}]$ \\
\hline Carbon fiber & 3.74 & 7.58 \\
Glass fiber & 3.05 & 6.62 \\
\hline
\end{tabular}

single fiber was clamped using $0.5 \mathrm{~mm}$ thick silicone rubber strips and glass plates, as depicted in Figure 2. By pouring the resin into the space of the stacking mold, a $1.0 \mathrm{~mm}$ thick composite plate, in which reinforcement fibers existed in the center, was fabricated. The poured resin was hardened using almost the same procedure described in the previous section without applying pressure. After hardening, the single fiber specimen was cut out from the plate, as shown in Figure 3, and the embedded single fiber was carefully aligned parallel to the longitudinal axis of the specimen.

\subsection{Dynamic and Static Cantilever Bending Test}

The energy absorption of the UD-FRP until failure was investigated under dynamic and static bending conditions. The specimen was gripped by a jig, and the bending load was applied statically and dynamically, as shown in Figure 4. The energy absorption of the specimen was calculated by measuring the area under the load-deflection curve until the bending load reached a maximum.

\subsubsection{Dynamic Cantilever Bending Test}

By using an Izod impact tester (Impact tester, Toyo Seiki), a dynamic bending test was conducted following JIS-K 7110. A dynamic bending load was applied by hitting the pivoting arm. The load of the specimen was measured by using strain gauge adhered on the proving arm. The load on the specimen was calculated from the strain based on the load-strain relationship obtained from the calibration experiment conducted in advance. The deflection of the specimen was also calculated based on the length of the arm and the pivoting angle obtained using rotary encoder (TRD-1200A, Koyo Electrics industries). 


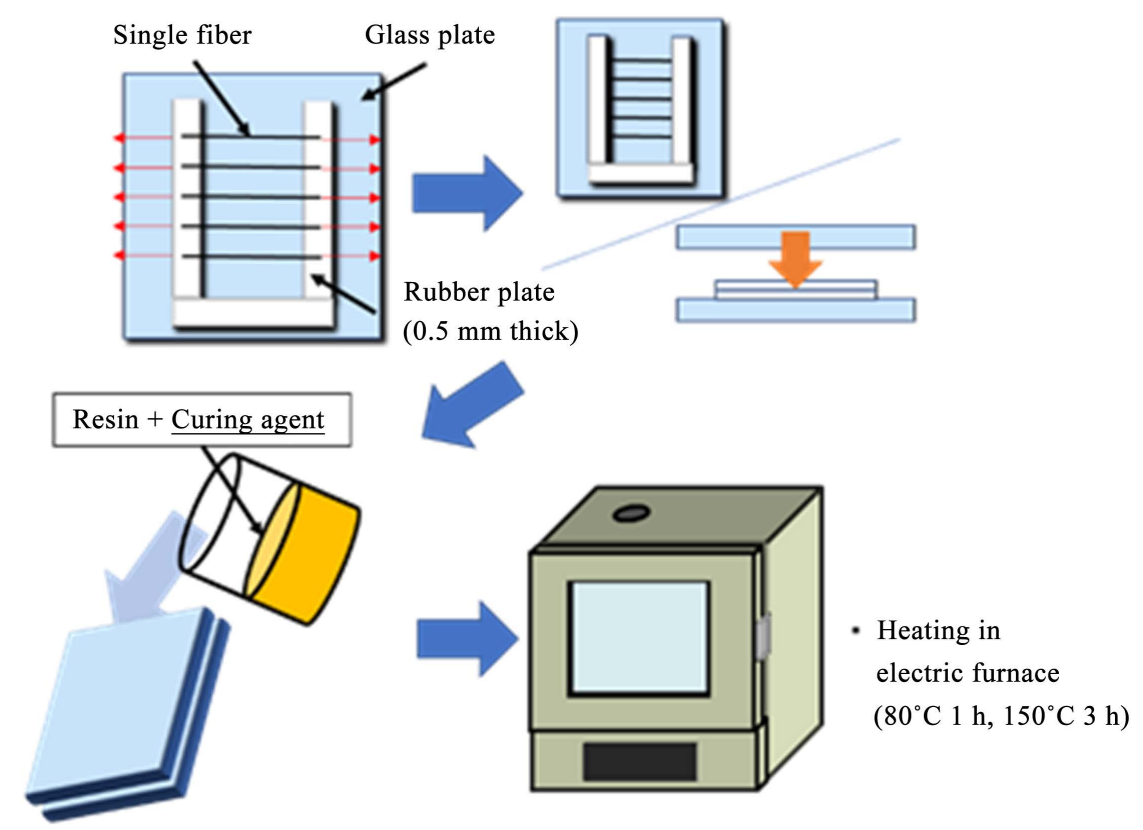

Figure 2. Fabrication methods of single fiber composite.

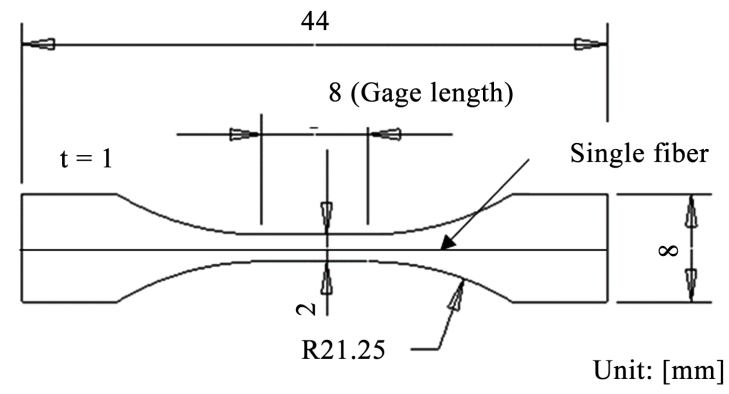

Figure 3. Specimen for fragmentation test.

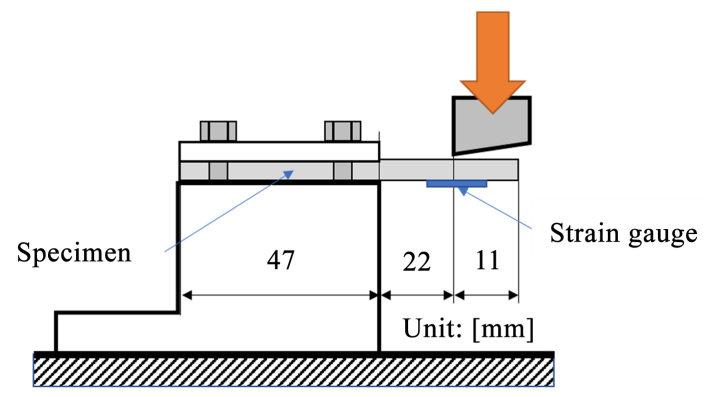

Figure 4. Schematic view of bending test.

\subsubsection{Static Cantilever Bending Test}

By using universal testing machine (Autograph, Shimadzu), the static bending test was conducted. The applied strain rate was controlled to $1.92 \times 10^{-4} / \mathrm{s}$. At least 10 specimens were tested.

\subsection{Fragmentation Test}

The interfacial shear strength (IFSS) between the fiber and matrix was investi- 
gated using static and dynamic fragmentation tests with a single fiber-embedded specimen. Tensile deformation was applied to the single-fiber embedded specimen to obtain multiple fractures of the embedded single fiber. The applied tensile strain was controlled to be $2 \%-4 \%$ against the gauge length of the specimen in order to avoid matrix fracture. After the application of tensile deformation, the embedded fiber breakage was observed using an optical microscope to measure the broken fiber length. The above procedures were repeated until the variation in average fragment length was below $10 \%$. The apparent IFSS was calculated using Equation (2) following the Kelly-Tyson model [8]. Here, the strength of the fractured fibers was corrected using the Weibull parameters of the fibers, as shown in Equation (3) [8].

$$
\begin{gathered}
\tau=\frac{D \sigma_{f}}{2 L_{c}}, L_{c}=\frac{4}{3} L_{\text {ave }} \\
\sigma_{f}=\left(\frac{L_{0}}{L_{c}}\right)^{\frac{1}{m_{f}}} \sigma_{0}
\end{gathered}
$$

where, $\tau$ is interfacial shear strength, $D$ is fiber diameter, $L_{c}$ and $L_{a v e}$ is critical fiber length and average fiber length, respectively.

\subsubsection{Static Fragmentation Test}

The IFSS between the fiber and matrix under static conditions was measured using a small tabletop universal testing machine (EZ-test, Shimadzu). The applied strain rate against the gauge length of the specimen was controlled to be $3.33 \times 10^{-4} / \mathrm{s}$. The IFSS was evaluated after testing a minimum of 5 specimens.

\subsubsection{Dynamic Fragmentation Test}

The IFSS between the fiber and matrix under dynamic conditions was measured using a tensile-type impact tester based on the split Hopkinson pressure bar (SHPB) method, as shown in Figure 5 [9] [10] [11]. The dynamic tensile load was applied by hitting the input bar (A5052, $\varnothing 20 \times 1500)$ using an impactor $($ A5052, $\varnothing 55(\varphi 30) \times 200)$ driven by air pressure. By controlling the applied air pressure and opening time of solenoid valve, the velocity of impactor was controlled in order to control the applied strain rate. When the impactor hits the input bar, the elastic stress wave propagates into the input bar to the output bar (A5052, $\varnothing 20 \times 1500$ ) through the specimen gripped by fixing the jig. Specimen is clamped by inserting it into the specimen shaped groove on the fixing jig, and then fastening with bolts at both ends of the jig. The applied stress waveowas measured by strain gauges adhered to both the input and output bars to evaluate the applied strain based on the one-dimensional elastic stress wave theory described in Equation (4) when the load on specimen was equal at both ends [11]. In this study, the average strain rate $\dot{\varepsilon}$ was applied to be 67.6 and $177 /$ s. The average strain rate was calculated using the slope of the strain-time diagram during deformation based on Equation (5). At least five specimens were tested to evaluate the IFSS under dynamic conditions. 


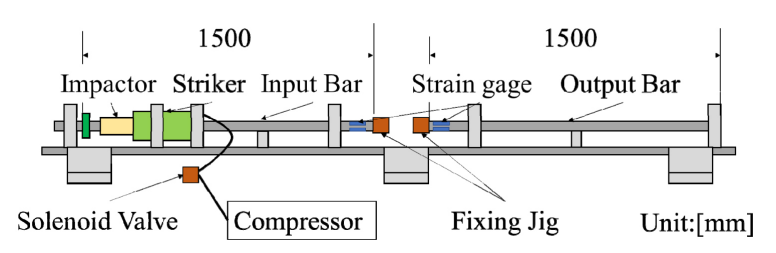

Figure 5. SHPB apparatus for dynamic fragmentation test.

$$
\begin{gathered}
\varepsilon=\frac{2 C_{b}}{L_{0}} \int\left[\varepsilon_{i}(t)-\varepsilon_{t}(t)\right] \mathrm{d} t, \sigma=\frac{A_{b}}{A_{s}} E \varepsilon_{t}(t) \\
\dot{\varepsilon}=\frac{2 C_{b}}{L_{0}}\left\{\varepsilon_{i}(t)-\varepsilon_{t}(t)\right\}
\end{gathered}
$$

where, $\varepsilon$ is strain on specimen, $C_{b}$ is propagating velocity of longitudinal waves, $E$ is Young's modulus of input/output bar, $A_{b}$ and $A_{s}$ are cross section area of input/output bar and specimen, $\varepsilon_{i}(t), \varepsilon_{t}(t)$ are incident and transmitted strain, respectively.

\section{Result and Discussion}

\subsection{Energy Absorption of FRP in Different Strain Rate}

Figure 6 illustrates a typical load-deflection diagram of UD-FRP under static and dynamic strain rate conditions. Despite the difference in the reinforcement fiber and type of matrix, when the bending load was applied at a static strain rate condition, the load increased almost linearly until the specimen failed. In contrast, when a bending load was applied at a dynamic strain rate condition, the load firstly increased linearly, similar to the static strain rate condition, and until the bending load reached a maximum, the slope of bending load-deflection diagram increased than that under static strain rate condition with increasing in deflection.

Figure 7 also depicts the amount of energy absorption of UD-FRP until failure under static and dynamic strain rate conditions. When comparing the test results of UD-FRP made with the original matrix at static strain rate conditions, there was no significant difference in the amount of energy absorption caused by the difference in the type of reinforcement fiber. As the strain rate increased, the amount of energy absorbed by the UD-FRP increased. Moreover, the increment in energy absorption was significantly increased when glass fiber was used as reinforcement by comparing the results of UD-FRP made with carbon fiber. When comparing the test results of UD-FRP made with the modified matrix, no significant differences appeared in the results of the static strain rate condition. However, under dynamic strain rate conditions, the amount of energy absorption of UD-FRP made with carbon fiber was significantly improved by modifying the matrix with sub-micron glass fiber.

Figure 8 shows the SEM observations of the fractured surface of the UD-FRP after the test. When UD-FRP was made with the original matrix, the smooth fiber surface was confirmed even when the strain rate was changed. In contrast, 


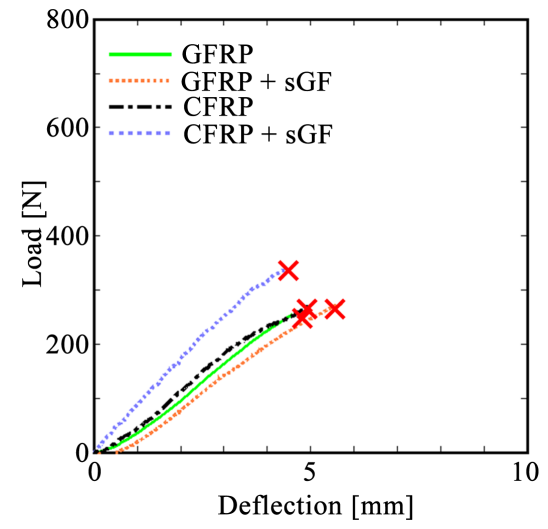

(a)

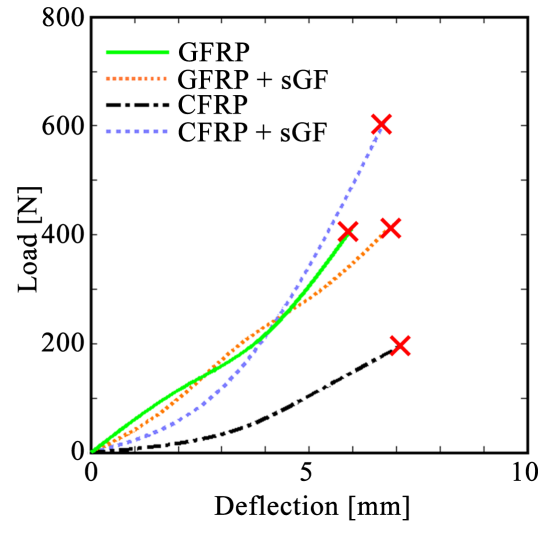

(b)

Figure 6. Load-deflection curves of FRP in different strain rates. (a) Static strain rate condition; (b) Dynamic strain rate condition.

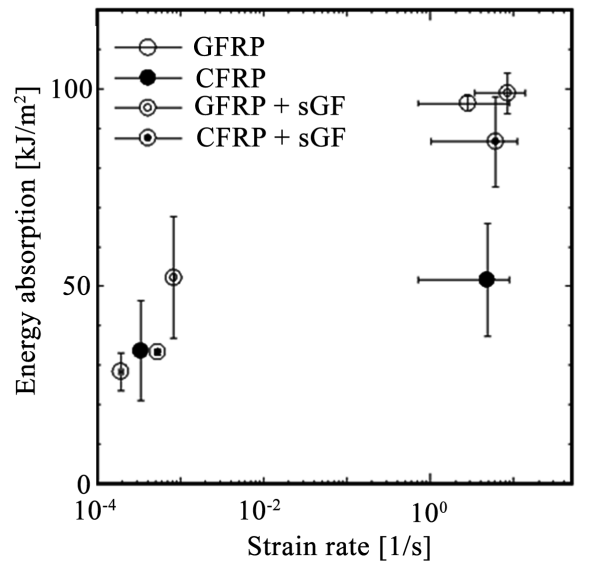

Figure 7. Energy absorption of FRP in different strain rates.

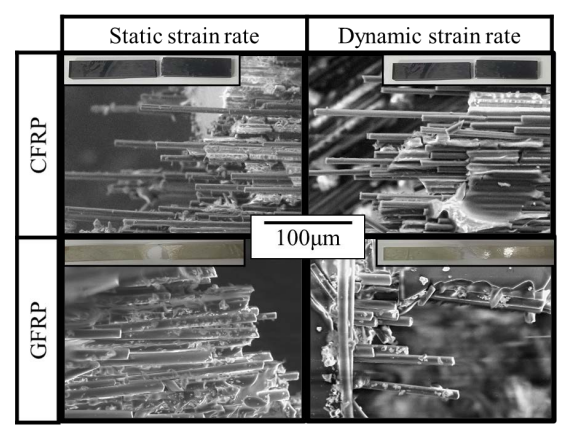

(a)

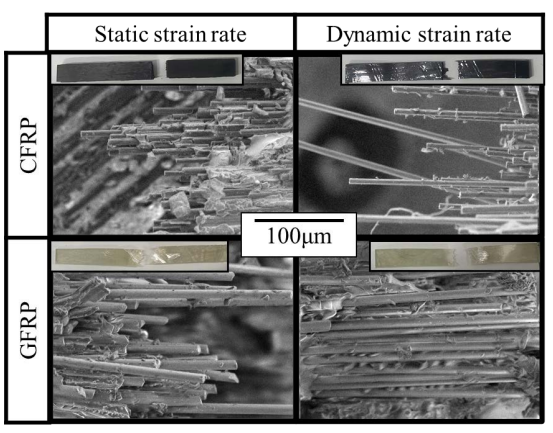

(b)

Figure 8. SEM observations of fractured surface. (a) FRP with original resin; (b) FRP with modified resin.

when UD-FRP was constructed with a modified matrix, the residue of the matrix was confirmed at the surface of the fibers, especially under dynamic strain rate conditions. These results suggest that the interfacial adhesion between the matrix and fiber under dynamic strain rate conditions was improved by incorporating sGF into the matrix. 


\subsection{IFSS between Reinforcement Fiber and Original Matrix}

Figure 9 presents a typical result of the stress-strain diagrams of the fragmentation test at different strain rate conditions. The test results showed that the slope of the stress-strain diagram increased with an increase in the strain rate. These results can be explained by the viscoelastic characteristics of the matrix [12] Figure 10 also depicts the interfacial shear strength between the embedded fiber and matrix with respect to the applied strain rate. The IFSS between the glass fiber and matrix increased with an increase in the applied strain rate, whereas that between the carbon fiber and matrix decreased with increasing applied strain rate. Generally, it is well known that the yield strength of polymers increases with increasing applied strain rate. Therefore, the IFSS results between the glass fiber and matrix could be explained by the change in the yield strength of the matrix with the change in the applied strain rate. However, the IFSS results between the carbon fiber and matrix could not be explained by the change in the yield strength of the matrix.

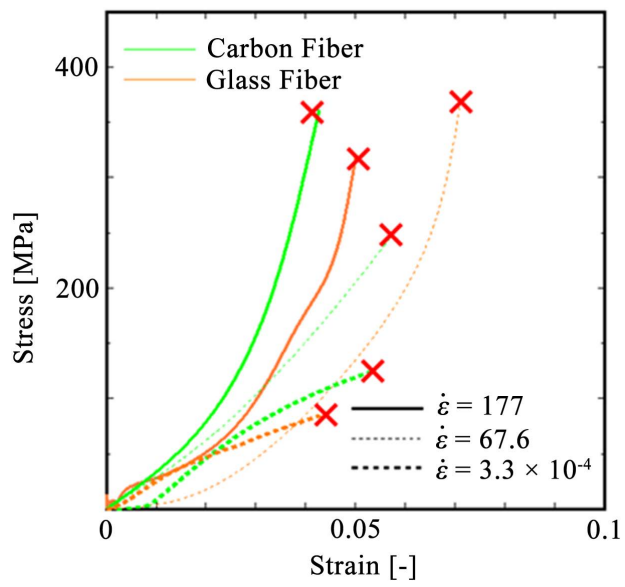

Figure 9. Typical stress-strain curves of SFC with original resin in different strain rate condition.

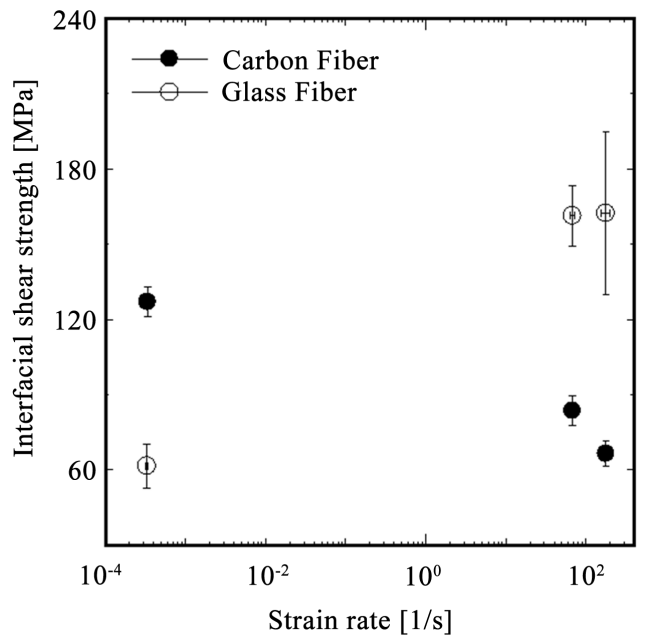

Figure 10. IFSS with respect to strain rate (carbon or glass fiber/original resin). 


\subsection{IFSS of SFC with Modified Resin}

Figure 11 presents a typical result of stress-strain diagrams of the fragmentation test with the modified matrix at different strain rate conditions. Stress-strain diagrams of the modified matrix showed almost the same tendency as that of the original matrix.

Figure 12 also shows the interfacial shear strength between the embedded fiber and modified matrix with respect to the applied strain rate. The IFSS between the glass fiber and modified matrix increased with an increase in the applied strain rate, and these values were almost the same as those between the glass fiber and original matrix. In contrast, the IFSS between the carbon fiber and modified matrix was almost constant, even when the applied strain rate was increased. In other words, the IFSS between the carbon fiber and the modified matrix was improved by the addition of sGF. These results suggest that the improvement in energy absorption of UD-FRP could be explained by the improvement in IFSS between the carbon fiber and modified matrix.

Figure 13 depicts a polarized microscope observation of the specimen around the embedded fiber. Under static strain rate conditions, the embedded fibers and

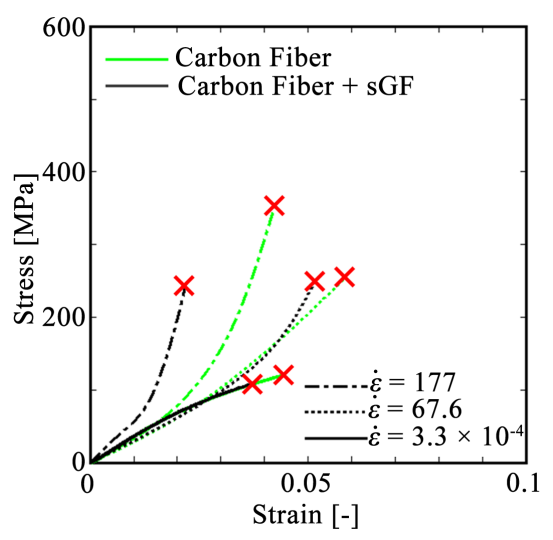

(a)

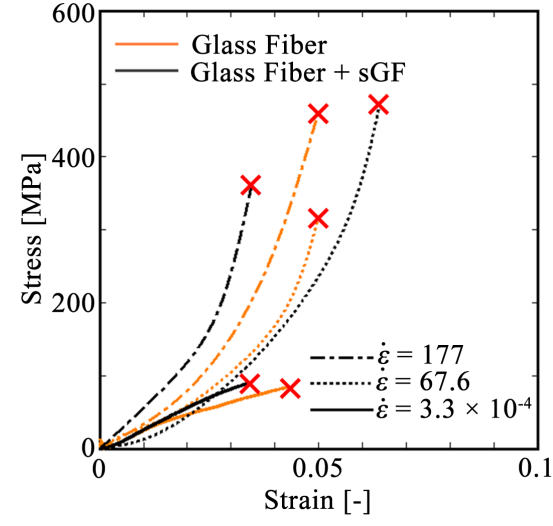

(b)

Figure 11. Typical stress-strain curves of SFC with original or modified resin.

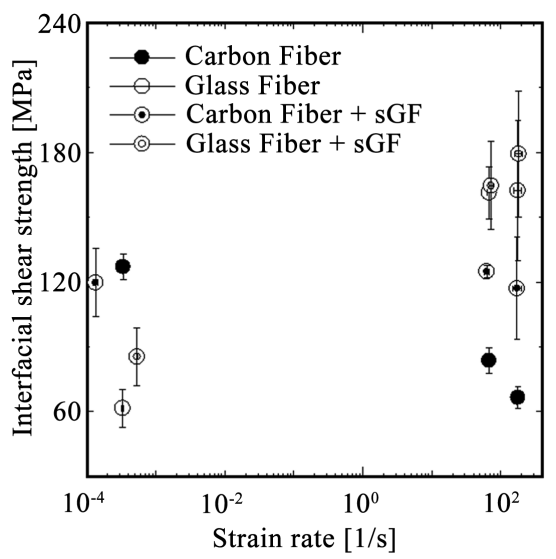

Figure 12. IFSS with respect to strain rate (carbon or glass fiber/original or modified re$\sin )$. 


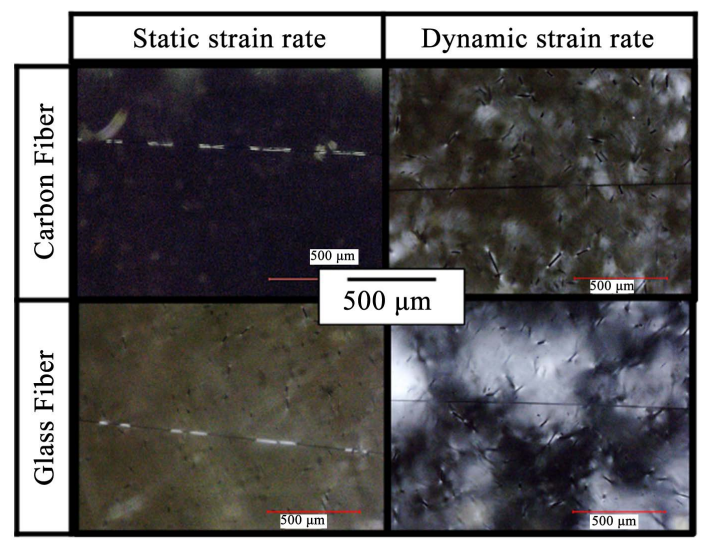

Figure 13. Observation of fragmentations of embedded fiber.

their fragmentation were clearly identified. Moreover, the matrix appears to be almost transparent. However, under dynamic strain rate conditions, the debonding of sGF and the matrix was confirmed. These results suggest that when a dynamic load is applied to the specimen, the debonding between the sGF and matrix occurred more frequently than fiber fragmentation. The fragmentation of reinforcement fiber could be suppressed because of the debonding between the sGF and matrix.

\section{Conclusions}

A study was conducted to investigate the relationship between the energy absorption of UD-FRP and the interfacial shear strength between the reinforcement fiber and matrix under various strain rate conditions. The following conclusions were drawn:

1) The energy absorption of UD-CFRP decreased with an increase in strain rate, whereas that of UD-GFRP increased with an increase in strain rate.

2) The interfacial shear strength between carbon fiber and epoxy matrix decreased with an increase in strain rate.

3) When the epoxy resin was modified by adding sub-micron glass fiber, both the interfacial shear strength between the carbon fiber and matrix, and the energy absorption of UD-CFRP improved.

4) When a dynamic load was applied to the FRP, debonding between the submicron glass fiber and matrix occurred more frequently than fiber fragmentation. The fragmentation of the reinforcement fiber could be suppressed because of the debonding between the submicron glass fiber and matrix.

5) Dynamic fragmentation test using SHPB method was an effective method to evaluate the interfacial shear strength between matrix and reinforcement fiber quantitatively.

\section{Acknowledgements}

The authors would like to thank Nippon Muki co., ltd. for their donation of sub-micron glass fiber. This work was partly supported by JSPS KAKENHI 
Grant Number 21K03779.

\section{Conflicts of Interest}

The authors declare no conflicts of interest regarding the publication of this paper.

\section{References}

[1] Abena, A., Soo, S.L. and Essa, K. (2017) Modelling the Orthogonal Cutting of UD-CFRP Composites: Development of a Novel Cohesive Zone Model. Composite Structures, 168, 65-83. https://doi.org/10.1016/j.compstruct.2017.02.030

[2] Feraboli, P., Masini, A., Taraborrelli, L. and Pivetti, A. (2007) Integrated Development of CFRP Structures for a Topless High Performance Vehicle. Composite Structures, 78, 495-506. https://doi.org/10.1016/j.compstruct.2005.11.011

[3] Chintada, V., Seela, C.R. and Matta, V.R. (2015) Modal and Static Analysis of Automotive Chassis Frame by Using FEA. International Journal of Applied Engineering Research, 10, 19775-19777.

[4] Harding, J. and Welsh, L.M. (1983) A Tensile Testing Technique for Fibre-Reinforced Composites at Impact Rates of Strain. Journal of Materials Science, 18, 1810-1826. https://doi.org/10.1007/BF00542078

[5] Rezaei, F., Yunus, R., Ibrahim, N.A. and Mahdi, E.S. (2008) Development of ShortCarbon-Fiber-Reinforced Polypropylene Composite for Car Bonnet. Polymer-Plastics Technology and Engineering, 47, 351-357.

[6] Odagiri, N., Kishi, H. and Yamashita M. (1996) Development of TORAYCA Prepreg P2302 Carbon Fiber Reinforced Plastic for Aircraft Primary Structural Materials. Advanced Composite Materials, 5, 249-252. https://doi.org/10.1163/156855196X00301

[7] Nagai, I., Tanaka, T., Matsukawa, M., Komaki, K. and Hojo, M. (1996) Effect of lay-Up Sequence on Relation between Damage and Absorbed Energy in CFRP Laminates Subjected to Falling Weight Impact. Journal of the Society of Materials Science, 45, 792-798. https://doi.org/10.2472/jsms.45.792

[8] Ogihara, S., Koike, Y., Maruyama, K., Kobayashi, S. and Kogo, Y. (2004) Effect of Loading Rate on Fiber Break Behavior in a Single Carbon Fiber Reinforced Plastic. Journal of the Society of Materials Science, 53, 667-672.

https://doi.org/10.2472/jsms.53.667

[9] Ogawa, K. and Sugiyama, F. (2004) Investigation of Impact Tensile Test Using the Split-Hopkinson Bar. Journal of the Society of Materials Science, 53, 560-565. https://doi.org/10.2472/jsms.53.560

[10] Amijima, S. and Fujii, T. (1976) Use of Split Hopkinson Pressure Bar Method to Impact Testing of FRP. Material, 25, 470-476. https://doi.org/10.2472/jsms.25.470

[11] Daimaruya, M., Kobayashi, H. and Tsuda, H. (2004) Discussions on Method of Impact Tension Test for Strip Specimen. Material, 53, 1240-1246.

https://doi.org/10.2472/jsms.53.1240

[12] Qasrawi, Y., Heffernan, P.J. and Fam, A. (2015) Dynamic Behavior of Concrete Filled FRP Tubes Subjected to Impact Loading. Engineering Structure, 100, 212-225.

https://doi.org/10.1016/j.engstruct.2015.06.012 